\title{
Subarachnoid haemorrhage: older patients have low cerebral blood flow
}

\author{
CARL H A MEYER, DEREK LOWE, MARCIA MEYER, PETER L RICHARDSON, \\ GLENN NEIL-DWYER
}

\begin{abstract}
Daily estimations of hemispheral cerebral blood flow using the xenon-133 inhalation technique were made in 116 patients during the first three weeks after subarachnoid haemorrhage. The patients' cerebral perfusion on average remained less than the normal perfusion expected for their age (based on a single estimation of cerebral blood flow in 67 volunteers). On each separate day after subarachnoid haemorrhage cerebral blood flow was inversely related to the patient's age. Older patients seem especially at risk of developing cerebral ischaemia after subarachnoid haemorrhage. The clinical outcome was more often unfavourable in older patientsthat is, in those who tended to have the lowest cerebral blood flow.

Present results support the view that episodes of low cerebral blood flow lead to a poor outcome after subarachnoid haemorrhage. Because of the risk of inducing cerebral ischaemia great care should be exercised by physicians administering hypotensive drugs to older patients after subarachnoid haemorrhage.
\end{abstract}

\section{Introduction}

Patients who survive a subarachnoid haemorrhage may suffer further disability or death from recurrent haemorrhages or cerebral ischaemia..$^{1-4}$ Cerebral ischaemia may occur, especially during the first two to three weeks after subarachnoid haemor-

South-east Thames Regional Neurosurgical Unit, Brook General Hospital, London SE18 4LW

CARL H A MEYER, BMEDSC, FRACs, senior neurosurgical registrar (present appointment: senior lecturer in neurosurgery, University of Birmingham) PETER L RICHARDSON, FRCs, neurosurgical registrar (present appointment: senior neurosurgical registrar, Maudsley Hospital, London)

GLENN NEIL-DWYER, MS, FRCS, consultant neurosurgeon

Medical Research Council Biostatistics Unit, Cambridge DEREK LOWE, MSc, statistician

Harborne, Birmingham

MARCIA MEYER, BA, research assistant rhage, whether or not surgery is performed to secure an aneurysm against recurrent haemorrhage. The eventual outcome of subarachnoid haemorrhage is more likely to be poor in older patients: this applies both to the natural history of the condition ${ }^{5-7}$ and to the results of surgery for ruptured aneurysms. ${ }^{8}$ This poses the question of whether the association between clinical outcome and patient age may be determined, in part at least, by changes occurring in cerebral blood flow after subarachnoid haemorrhage. Is there a particular risk that older patients may develop cerebral ischaemia? If so, does this affect their management by referring physicians and by neurosurgeons? We present a study of cerebral blood flow during the first three weeks after subarachnoid haemorrhage.

\section{Subjects and methods}

PATIENTS

During 1978-80, 116 patients ( 36 men, 80 women) aged 22-66 years (mean $47+$ SD 11 years) were admitted to medical units and transferred to this regional neurosurgical unit as soon as possible after subarachnoid haemorrhage had been diagnosed. No patient suffered from established pulmonary or cardiovascular disease. The patients were nursed in bed, fed an unrestricted ward diet, and given a fluid input of 2-3 1 daily.

The day, ending at midnight, on which subarachnoid haemorrhage occurred was referred to as day 1 . Subsequent days, beginning at midnight, were then numbered consecutively. Daily estimations of hemispheral cerebral blood flow were made as often as possible between days 2 and 21 . Individual patients, however, could not be studied on every single day during this period. Some patients, for example, were not referred until the second week after subarachnoid haemorrhage, some patients died before day 21 , and some readings were missed for technical reasons.

Patients were given codeine (for pain) and phenytoin (as a prophylactic anticonvulsant). Further drug treatment was determined by the policy of whichever of three neurosurgeons was on duty when patients entered the unit. All 28 patients admitted under one surgeon were given tranexamic acid $(6 \mathrm{~g} /$ day $)$, which was stopped if angiography failed to show an aneurysm, if an aneurysm responsible for subarachnoid haemorrhage was successfully clipped at operation, or six weeks after the haemorrhage, whichever was applicable. Of the patients admitted under the two other surgeons, those who were admitted to the unit on days 1-3 were entered in a randomised double-blind trial (not reported here) concerned with the effects of 
adrenergic-blocking drugs on the clinical course of subarachnoid haemorrhage. In all, 16 patients were given propranolol ( $80 \mathrm{mg}$ eighthourly) and phentolamine ( $20 \mathrm{mg}$ three-hourly) while 17 patients were given only the propranolol. Adrenergic blockade was continued until after day 21 . Apart from codeine and phenytoin no drug was given to the 55 other patients (including some of those admitted during days 1-3 and all of those admitted after day 3).

The source of subarachnoid haemorrhage was determined by cerebral angiography and was: cerebral aneurysm (92 patients) situated on the internal carotid artery (30), the middle cerebral artery (23), the anterior communicating artery complex (27), the pericallosal artery (four), and the vertebrobasilar system (eight); and cerebrovascular malformation (five). No source was found in 19 patients. In all, 124 angiograms were performed between days 2 and 20 (median, day 7). Craniotomy for treatment of a ruptured aneurysm was performed in 45 patients. Overall, there were 48 operations on days 3-20 (median, day 12). On days when surgery or angiography was done cerebral blood flow was studied before the procedure was carried out.

The eventual clinical outcome was assessed three months after the initial subarachnoid haemorrhage (see table I). horizontal, resting quietly under conditions (including lighting and noise) that were similar from day to day. Subjects inhaled a mixture of ${ }^{133} \mathrm{Xe}\left(3 \mathrm{mCi}\right.$ ), air, and oxygen through a rebreathing circuit ${ }^{10}$ from which carbon dioxide was absorbed by soda lime. The carbon dioxide tension of end-tidal expired air $\left(\mathrm{PeCO}_{2}\right)$ was measured with an infrared analyser. After two minutes of inhalation the subjects began breathing air through an open circuit and ${ }^{133} \mathrm{Xe}$ was cleared from the body.

During the first three minutes of the desaturation phase the clearance of ${ }^{133} \mathrm{Xe}$ from the head was monitored by two external detectors each with a sodium iodide crystal $(25 \mathrm{~mm} \times 25 \mathrm{~mm})$ and a parallel hole lead collimator ( $25 \mathrm{~mm}$ diameter, $50 \mathrm{~mm}$ length). On each side of the head a collimator was placed firmly against the scalp midway between the external auditory meatus and the vertex and pointing towards the middle of the cranial cavity. The clearance of ${ }^{133} \mathrm{Xe}$ was also recorded from the expired air. Cerebral blood flow ( $\mathrm{ml}$ blood/100 $\mathrm{g}$ brain/min) was determined using nomograms ${ }^{11}$ for deconvolutional analysis of the Xe clearance curves. With this technique cerebral blood flow is estimated for a fairly large cone of cerebral tissue, including grey and white matter, underlying an extracranial detector. ${ }^{12} 13$

By using the two detectors cerebral blood flow was estimated

TABLE I-Clinical outcome of subarachnoid haemorrhage (assessed by interview and by clinical examination three months after initial haemorrhage)

\begin{tabular}{|c|c|c|c|c|c|c|c|}
\hline \multirow{2}{*}{$\begin{array}{l}\text { Age group } \\
\text { (years) }\end{array}$} & \multirow{2}{*}{$\begin{array}{c}\text { No of } \\
\text { patients }\end{array}$} & \multicolumn{3}{|c|}{ Drug treatment } & \multicolumn{3}{|c|}{ Clinical outcome* } \\
\hline & & $\begin{array}{c}\text { Tranexamic } \\
\text { acid }\end{array}$ & $\begin{array}{c}\text { Adrenergic } \\
\text { blockade }\end{array}$ & None & Excellent & Acceptable & Poor \\
\hline \multicolumn{8}{|c|}{ Subarachnoid haemorrhage from all sources $(n=105) \dagger$} \\
\hline $\begin{array}{l}20-49 \\
50-66\end{array}$ & $\begin{array}{l}58 \\
47\end{array}$ & $\begin{array}{l}16 \\
10\end{array}$ & $\begin{array}{c}18 \\
12 \\
=1 \cdot 5, \mathrm{df} 2,\end{array}$ & $\begin{array}{l}24 \\
25\end{array}$ & $\begin{array}{l}35 \\
14\end{array}$ & $\begin{array}{c}11 \\
13 \\
10 \cdot 1, \text { df } 2, p\end{array}$ & $\begin{array}{l}12 \\
20\end{array}$ \\
\hline $\begin{array}{l}20-49 \\
50-66\end{array}$ & $\begin{array}{l}42 \\
40\end{array}$ & $\begin{array}{c}\text { arachnoid haem } \\
10 \\
9\end{array}$ & $\begin{array}{c}\text { hage from an } \\
15 \\
9 \\
=2 \cdot 2 \text { df } 2,\end{array}$ & $\begin{array}{c}\text { shown } \\
17 \\
22\end{array}$ & $\begin{array}{c}\text { graphy }(n= \\
23 \\
10\end{array}$ & $\begin{array}{r}7 \\
10 \\
7 \cdot 6, \text { df } 2, p<\end{array}$ & $\begin{array}{l}12 \\
20\end{array}$ \\
\hline
\end{tabular}

-Outcome classified as: excellent-apparently full recovery; acceptable-mild residual deficit, but patients physically independent and capable of employment (or able to run a home) without requiring supervision or custodial care; or poor-patients capable of self-care but requiring supervision of activities, or not capable of self-care and/or severely disabled by dementia or dysphasia, or dead within three months (this last group comprised six patients in each age group). †Table excludes eleven patients (see Results).

TABLE II-Lowest mean cerebral blood flow on any one day, and clinical outcome

\begin{tabular}{|c|c|c|c|c|c|}
\hline \multirow{2}{*}{$\begin{array}{c}\text { Age group } \\
\text { (years) }\end{array}$} & \multirow{2}{*}{$\begin{array}{l}\text { Median No of daily } \\
\text { estimations of mean } \\
\text { cerebral blood flow } \\
\text { (and interquartile range) }\end{array}$} & \multirow{2}{*}{$\begin{array}{l}\text { Lowest mean } \\
\text { cerebral blood flow } \\
(\mathrm{ml} / 100 \mathrm{~g} / \mathrm{min})\end{array}$} & \multicolumn{3}{|c|}{ Clinical outcome (No (\%)) } \\
\hline & & & Excellent & Acceptable & Poor \\
\hline \multicolumn{6}{|c|}{ All drug groups $(n=105)$} \\
\hline $20-49$ & $11(6-16)$ & $\left\{\begin{array}{c}<25 \\
25-29 \cdot 5 \\
30-34 \cdot 5 \\
\geqslant 35 \\
<25 \\
25-29 \cdot 5 \\
30-34 \cdot 5 \\
\geqslant 35\end{array}\right.$ & 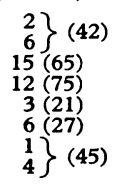 & $\begin{array}{l}1 \\
2 \\
5(22) \\
3(19) \\
3(21) \\
6(27) \\
\left.\begin{array}{l}4 \\
0\end{array}\right\}(36)\end{array}$ & 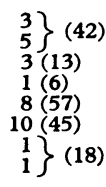 \\
\hline \multicolumn{6}{|c|}{ Patients not receiving drugs $(n=50$ ) } \\
\hline $50-66$ & $12(6-16)$ & $\left\{\begin{array}{c}<25 \\
25-29 \cdot 5 \\
30-34.5 \\
\geqslant 35 \\
<25 \\
25-29 \cdot 5 \\
30-34.5 \\
\geqslant 35\end{array}\right.$ & $\left.\begin{array}{l}1 \\
0 \\
6 \\
6 \\
0 \\
4 \\
1 \\
3\end{array}\right\}\left(\begin{array}{l}(17) \\
(67) \\
(44)\end{array}\right.$ & $\left.\begin{array}{l}0 \\
0 \\
4 \\
0 \\
3 \\
1 \\
3 \\
0\end{array}\right\}(22)$ & $\left.\begin{array}{l}1 \\
4 \\
1 \\
1 \\
2 \\
7 \\
1 \\
1\end{array}\right\} \begin{array}{l}(83) \\
(11) \\
(53) \\
(22)\end{array}$ \\
\hline
\end{tabular}

\section{CONTROLS}

A single estimation of cerebral blood flow was made for each of 67 volunteers ( 33 men, 34 women) aged $20-73$ years (mean $42 \pm$ SD 14 years), all of whom were fully alert and not taking any medication. None had ever suffered from any known neurological, cardiovascular, or pulmonary disease.

\section{ESTIMATION OF CEREBRAL BLOOD FLOW}

Hemispheral cerebral blood flow was estimated using a method ${ }^{\bullet}$ that combined the inhalation of xenon-133 with analysis of the initial slope of the clearance of ${ }^{133} \mathrm{Xe}$ from the body. Subjects lay supine and simultaneously from the temporal region on each side of the head; the average of these two values was taken (mean cerebral blood flow). No attempt was made to adjust the readings to allow for $\mathrm{PeCO}_{2}$. At the time of measurement of cerebral blood flow blood pressure was determined from the brachial artery using a pressure cuff sphygmomanometer. Mean arterial blood pressure was calculated as the sum of the diastolic blood pressure and one-third of the pulse pressure.

\section{STATISTICAL METHODS}

Standard statistical procedures were used-namely, the $\chi^{2}$ test $^{14}$ and the correlation and regression technique. ${ }^{15}$ Significance implies a probability more extreme than $\mathrm{p}=0.05$ (two-tailed test). 


\section{Results}

MEAN CEREBRAL BLOOD FLOW IN CONTROLS

The resting mean cerebral blood flow in the controls, estimated in each case with $\mathrm{PeO}_{2}$ between 4.0 and $6.5 \mathrm{kPa}(30$ and $49 \mathrm{~mm} \mathrm{Hg}$ ), was inversely related to age (fig 1 ).

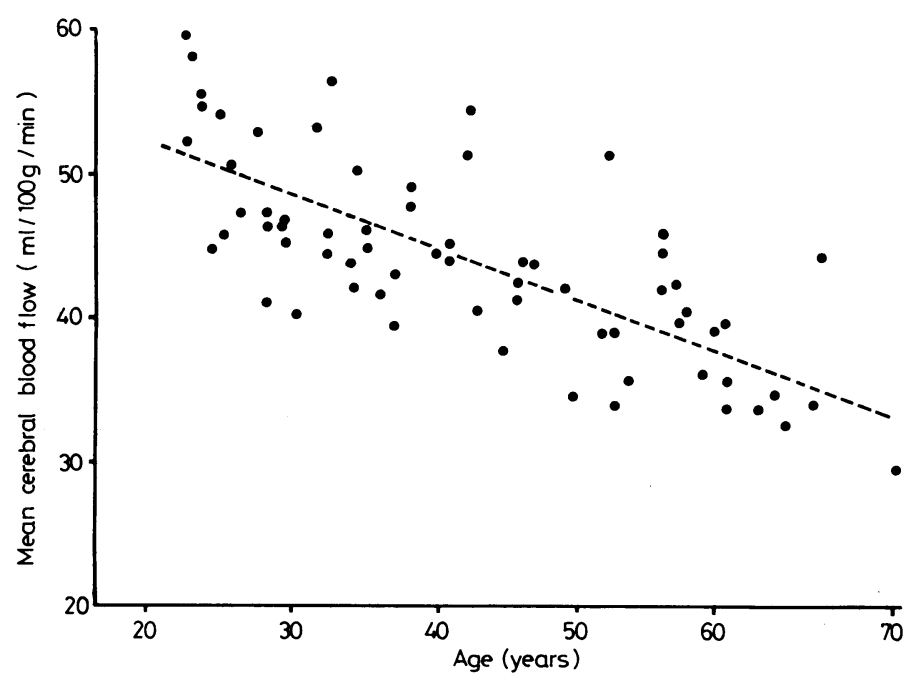

FIG 1 -Relation between mean cerebral blood flow and age in controls $(n=67, r=-0.73, p \ll 0 \cdot 001)$.

Regression line: Mean cerebral blood flow $=59 \cdot 1-0.34$ age

\section{MEAN CEREBRAL BLOOD FLOW IN PATIENTS}

\section{Relation with age}

When all patient's with subarachnoid haemorrhage were considered, regardless of drug treatment, resting mean cerebral blood flow was inversely related to patient age for each of the days between days 2 and 21 . The number of patients tested on each day ranged from 46 to 74 (median 66), and the linear correlation coefficients ranged from -0.48 to -0.71 (median -0.56 ) (in each case $p<0.001$ ). The coefficients were virtually unchanged by adjustment for end-tidal $\mathrm{P}_{\mathrm{e}} \mathrm{CO}_{2}$ or for mean arterial blood pressure.

The fall in mean cerebral blood flow with advancing age was not exaggerated by including patients taking tranexamic acid or adrenergicblocking drugs. When the relation between mean cerebral blood flow and age was considered for each drug group separately the linear correlation coefficients on individual days varied as follows: patients receiving no drugs, range -0.49 to -0.80 (median -0.59 ); patients receiving adrenergic blockade, -0.49 to -0.81 (median -0.62 ); and patients receiving tranexamic acid, -0.04 to -0.83 (median -0.43 ). The number of patients tested daily varied as follows: patients receiving no drugs, range 16-35 (median 29); patients receiving adrenergic blockade, 20-27 (median 23); and patients receiving tranexamic acid, 8-16 (median 11).

\section{Relation with time after haemorrhage}

On most days the patients studied included some who had undergone angiography and a few who had undergone surgery for aneurysm during the previous few days. No patient studied on day 2 , however, had undergone either procedure, and only two of those studied on day 3 had undergone angiography. On each of these days the association between mean cerebral blood flow and age was strong (all patients regardless of drug group: on day $2 n=46, r=-0.71$; on day $3 n=50$, $\mathbf{r}=-0.65$ ). Figure 2 shows values of mean cerebral blood flow on day 5 ; the scatter was typical of that occurring on other days. On the whole, regression lines for days 2-21 (fig 3) were roughly parallel. There was a progressive downward trend in mean cerebral blood flow during the first week after subarachnoid haemorrhage, a trend observable for each of the three drug groups considered separately.

The linear relation between mean cerebral blood flow and age was similar in both the patients and controls (similar slopes of regression lines in fig 3), but after subarachnoid haemorrhage cerebral blood

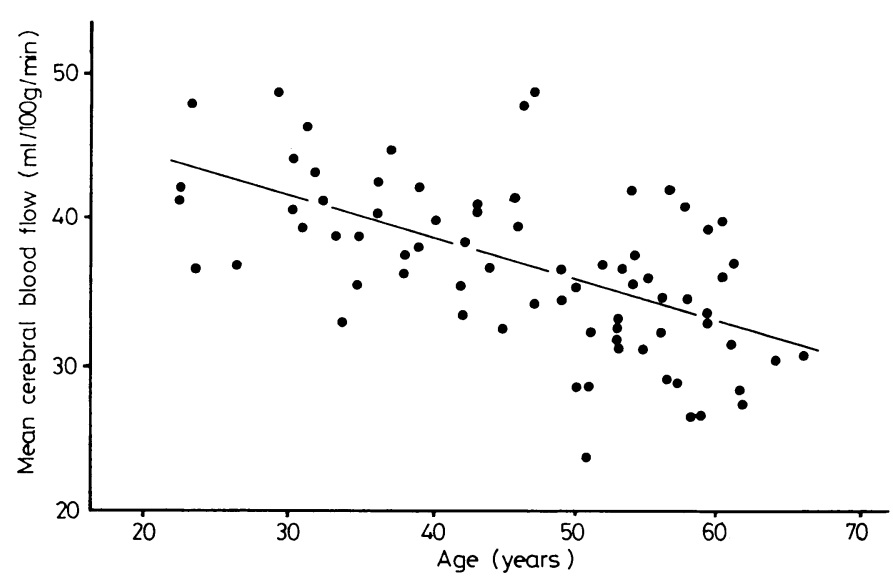

FIG 2-Mean cerebral blood flow plotted in patients on day 5 after haemorrhage $(n=74, r=-0.58, p \ll 0.001)$.

Regression line: Mean cerebral blood flow $=50 \cdot 3-0 \cdot 28$ age

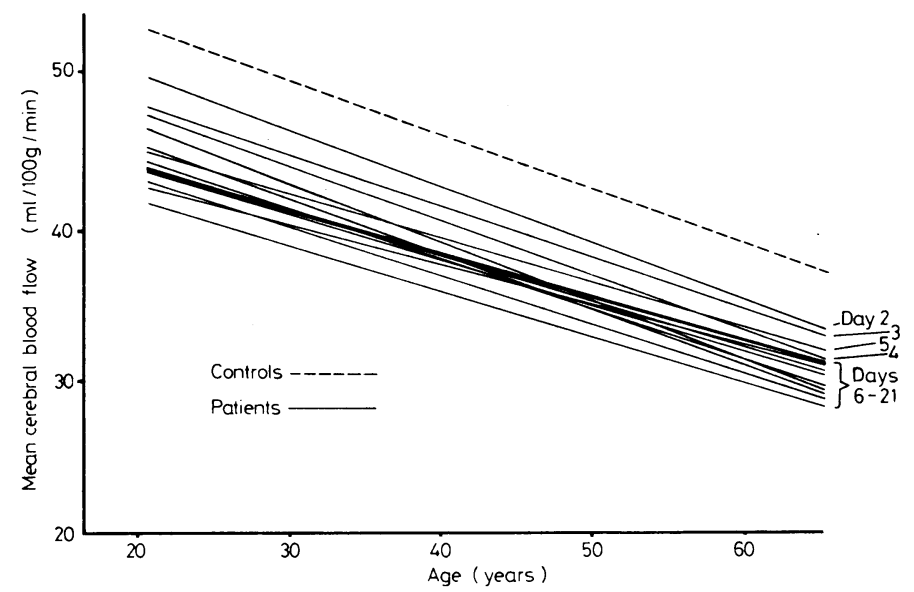

FIG 3-Regression lines describing relation between mean cerebral blood flow and age in patients for each of days 2-21 after haemorrhage and controls.

flow was reduced (different positions of regression lines) by an amount that for any single day was constant regardless of patient age.

\section{CLINICAL OUTCOME OF SUBARACHNOID HAEMORRHAGE}

In considering clinical outcome we excluded 11 patients-namely four whose deaths followed directly from surgical mishap (aneurysmal rupture during operation), four whose deaths were due to spontaneous recurrent haemorrhage (confirmed by lumbar puncture or computed axial tomography of the brain or both), and three whose eventual outcome could not be traced.

\section{Relation with age}

The outcome was less good in patients aged 50-66 years than in patients aged 20-49 years (table I). This was so whether we considered patients with subarachnoid haemorrhage from any source or only those whose haemorrhage came from aneurysms shown by angiography. The two age groups did not differ significantly in the relative numbers of patients taking trantxamic acid, adrenergic blockade, or no drugs.

\section{Relation with mean cerebral blood flow}

Since the number of daily estimations of cerebral blood flow (median 12) made during the three weeks after subarachnoid haemorrhage differed among the patients some caution is needed in interpreting table II, which gives the lowest daily value of cerebral blood 
flow in each patient. When all patients were considered regardless of drug treatment very low cerebral blood flow was linked with poor clinical outcome whether patients were young or old and was more common in the older patients. When the lowest mean cerebral blood flow was $\geqslant 30 \mathrm{ml} / 100 \mathrm{~g} / \mathrm{min}$ the outcome tended to be better, but the older patients were less likely to have an excellent outcome than those who were younger. These observations remained the same when patients who received no drugs were studied on their own.

\section{Discussion}

Our findings in normal subjects studied under resting conditions confirm that cerebral blood flow falls with advancing age. ${ }^{1016-18}$ In particular, the values of normocapnic cerebral blood flow and its decline with age were similar to results obtained by others using the same method for calculating cerebral blood flow. ${ }^{16}$

Our results indicate that cerebral blood flow falls progressively below normal during the first week after subarachnoid haemorrhage and remains abnormally low for at least another two weeks. For each separate day during this period the oldest patients tend to have the lowest cerebral blood flow. We found this to be so whether patients were treated with adrenergic blockade, tranexamic acid, or neither of these. Treatment with adrenergic-blocking drugs or tranexamic acid did not selectively depress the cerebral blood flow of the older patients.

This study supports the view ${ }^{5-8}$ that subarachnoid haemorrhage is more likely to have a poor outcome in older patients. Even when cerebral blood flow was relatively preserved (lowest mean value $\geqslant 30 \mathrm{ml} / 100 \mathrm{~g} / \mathrm{min}$ ) the overall outcome was worse in patients aged over 50 , which suggests that age-related factors other than resting cerebral blood flow may influence the clinical result. The relevance of cerebral blood flow, however, seems beyond question. Whether patients were young or old, very low mean cerebral blood flow ( $<30 \mathrm{ml} / 100 \mathrm{~g} / \mathrm{min}$ ) was associated with a poor, clinical outcome. Such very low values occurred more commonly in the older patients. This suggests that the occurrence of very low flow is important in determining the association between clinical outcome and age.

The level of cerebral blood flow that is critical for neurological function depends on factors such as the speed with which the flow falls, the period for which it remains low, the part of the brain affected, and the state of cerebral metabolism. As cerebral perfusion falls below $20 \mathrm{ml} / 100 \mathrm{~g} / \mathrm{min}$, however, rapid changes in neurological function occur that may progress to neuronal death. ${ }^{10-22}$ By lowering cerebral blood flow subarachnoid haemorrhage reduces the margin that normally exists between a subject's cerebral blood flow and the ischaemic threshold. In general, older patients come closer than younger patients to the threshold for cerebral ischaemia. Subarachnoid haemorrhage is also associated with impairment of the cerebrovascular reactivity (autoregulation) that normally prevents cerebral blood flow from falling when cerebral perfusion pressure is reduced. ${ }^{23-27}$ When autoregulation is lost after subarachnoid haemorrhage cerebral blood flow may fall further if systemic blood pressure is reduced, whether spontaneously or as a result of therapeutic measures, or if there is narrowing ("vasospasm") of intracranial arteries. In such circumstances patients who are old would be more vulnerable since their cerebral blood flow would have less far to fall before reaching the ischaemic threshold.

What are the clinical implications? Physicians faced with patients after a recent subarachnoid haemorrhage are concerned with their initial management and subsequent referral to a neurosurgical unit. Some workers advise that the likelihood of further bleeding from an (unclipped) aneurysm may be reduced by deliberately lowering the arterial blood pressure. ${ }^{28-30}$ This measure, however, may lead to cerebral ischaemia, especially in older patients, who, with their cerebral blood flow already low after the haemorrhage, are particularly vulnerable to the added effects of hypovolaemia and hypotension.

Whatever the patient's age, the risk of recurrent haemorrhage from a ruptured aneurysm is best countered by operative treatment of the aneurysm, provided that the patient is fit for surgery. In managing older patients (before, during, and after surgery) it should be remembered that the low (and falling) cerebral blood flow may well be a major factor in determining the outcome. Accordingly, particular care should be taken to avoid prolonged hypotension during surgery, to ensure good hydration at all times, and to ensure adequate pulmonary function (brains at risk from ischaemia should not be further threatened by hypoxia).

Ideally, surgery for a ruptured aneurysm should be performed soon after the initial subarachnoid haemorrhage to pre-empt recurrent haemorrhage and at a time when the risk of operative complications such as ischaemia is acceptably low. In individual patients the progressive fall in cerebral blood flow during the first week or two after subarachnoid haemorrhage may ultimately render the blood flow sufficiently low to compromise operations for ruptured aneurysms or to impair the clinical state so that surgery is deferred (with the risk that further haemorrhage will occur during the delay). This emphasises that clinically fit patients should be referred to neurosurgeons soon after their initial haemorrhage, within the first day if possible. This practice is widely accepted for patients who are young but also applies to patients who are older and whose low levels of cerebral blood flow may make the timing of angiography and surgery particularly critical. Clearly these older patients require careful management.

We thank Mr J R Bartlett and Mr R S Maurice-Williams for allowing us to study patients admitted under their care; $\mathrm{Dr} \mathrm{N}$ Veall, $\mathrm{Mr} \mathrm{J}$ Crawley, and Dr I James for advice concerning the estimation of cerebral blood flow; and Miss P Frost and Mr M Cowan for technical aid.

\section{References}

1 Tomlinson BE. Brain changes in ruptured intracranial aneurysm. $\mathcal{F}$ Clin Pathol 1959;12:391-9.

2 Smith B. Cerebral pathology in subarachnoid haemorrhage. $f$ Neurol Neurosurg Psychiatry 1963;26:535-9.

${ }^{3}$ Crompton MR. Cerebral infarction following the rupture of cerebral berry aneurysms. Brain 1964;87:263-79.

4 Crompton MR. The pathogenesis of cerebral infarction following the rupture of cerebral berry aneurysm. Brain $1964 ; 87: 491-510$.

5 Burry HC, Riley CG. Subarachnoid haemorrhage. A follow-up study of 109 cases admitted during a five year period. NZ Med $\mathcal{f} 1966 ; 65: 423-8$.

6 Keller AZ. Hypertension, age and residence in the survival with subarachnoid haemorrhage. Am ₹ Epidemiol 1970;91:139-47.

${ }^{7}$ Martindale BV, Garfield J. Subarachnoid haemorrhage above the age of 59: are intracranial investigations justified ? $\mathrm{Br}$ Med f 1978;i :465-6.

${ }^{8} \mathrm{i}$ Fortuny LA, Adams CBT, Briggs $M$. Surgical mortality in an aneurysm population: effects of age, blood pressure and preoperative neurological state. 7 Neurol Neurosurg Psychiatry 1980;43:879-82.

- Wyper DJ, Lennox GA, Rowan JO. Two minute slope inhalation technique for CBF measurement in man. $\mathcal{F}$ Neurol Neurosurg Psychiatry $1976 ; 29: 141-6$.

${ }^{10}$ Crawley JCW, Veall N. Recent developments in the ${ }^{133}$ xenon inhalation technique for cerebral flow. Journal of Nuclear Biology and Medicine 1975;19:205-12.

11 Wyper DJ, Rowan JO. The construction and use of nomograms for cerebral blood flow calculation using a ${ }^{133} \mathrm{Xe}$ inhalation technique. Phys Med Biol 1976;21:406-13.

12 Mallett BL, Veall N. The measurement of regional cerebral clearance rates in man using xenon ${ }^{133}$ inhalation and extracranial recording. Clin Sci 1965;29:179-91.

13 James IM. Methods for assessment of the effect of drugs on cerebral blood flow in man. Br $\mathcal{F}$ Clin Pharmacol 1979;7:3-12.

14 Siegel S. Nonparametric statistics for the behavioural sciences. London: McGraw-Hill, 1956.

15 Snedecor GW, Cochran WG. Statistical methods. 6th ed. Iowa: Iowa State University Press, 1967.

16 Dandona P, James IM, Newbury PA, Woollard ML, Beckett AG. Cerebral blood flow in diabetes mellitus: evidence of abnormal cerebrovascular reactivity. Br Med f 1978;ii:325-6.

17 Yamaguchi F, Meyer JS, Sakai F, Yamamoto M. Normal human aging and cerebral vasoconstrictive responses to hypocapnia. 7 Neurol $\mathrm{Sci}$ 1979;44 :87-94.

${ }^{18}$ Melamed E, Lavy S, Bentin S, Cooper G, Rinot Y. Reduction in regional cerebral blood flow during normal aging in man. Stroke 1980;11:31-5.

19 Trojaborg W, Boysen G. Relation between EEG, regional cerebral blood

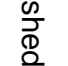 .

\section{.}


flow and internal carotid artery pressure during carotid endarterectomy. Electroencephalogr Clin Neurophysiol 1973;34:61-9.

${ }^{20}$ Branston NM, Strong AJ, Symon L. Extracellular potassium activity, evoked potential and tissue blood flow. $\mathcal{F}$ Neurol Sci 1977;32:305-21.

${ }^{21}$ Sundt TM Jr, Szurszewski J, Sharbrough FW. Physiological considerations important for the management of vasospasm. Surg Neurol 1977; 7:259-67.

${ }^{22}$ Ingvar DH, Lassen NA. Cerebral function, metabolism and blood flow. Acta Neurol Scand 1978;57:262-9.

${ }^{23}$ Heilbrun MP, Olesen J, Lassen NA. Regional cerebral blood flow studies in subarachnoid haemorrhage. $\mathcal{F}$ Neurosurg 1972;37:36-44.

${ }^{24}$ Nornes H, Knutzen HB, Wikeby P. Cerebral arterial blood flow and aneurysm surgery. II. Induced hypotension and autoregulatory capacity. f Neurosurg 1977;47:819-27.

${ }^{25}$ Symon L. Disordered cerebrovascular physiology in aneurysmal subarachnoid haemorrhage. Acta Neurochir (Wien) 1978;41:7-22.
26 Ishii R. Regional cerebral blood flow in patients with ruptured intracranial aneurysms. F Neurosurg 1979;50:587-94.

${ }^{27}$ Pickard JD, Boisvert DPJ, Graham DI, Fitch W. Late effects of subarachnoid haemorrhage on the response of the primate cerebral circulation to drug-induced changes in arterial blood pressure. $f$ Neurol Neurosurg Psychiatry 1979;42:899-903.

${ }^{28}$ Slosberg $\mathrm{P}$. Hypotensive therapy in acute intracranial bleeding. Mt Sinai f Med (NY) 1956;23:825-31.

${ }^{29}$ Ransohoff J, Goodgold A, Benjamin MV. Preoperative management of patients with ruptured intracranial aneurysms. F Neurosurg 1972;36: 525-30.

${ }^{30}$ Flamm ES. Parasurgical treatment of aneurysms. Clin Neurosurg 1977; $24: 240-7$

\title{
Disseminated malignant phaeochromocytoma: localisation with iodine-131-labelled meta-iodobenzylguanidine
}

\author{
HELEN SUTTON, PAUL WYETH, A P ALLEN, O A THURTLE, T K HAMES, M I D CAWLEY, \\ DUNCAN ACKERY
}

\begin{abstract}
Meta-iodobenzylguanidine, a guanethidine analogue, is a newly synthesised substance capable of imaging the adrenal medulla. In a woman in whom phaeochromocytoma had been diagnosed iodine-131-labelled metaiodobenzylguanidine was given intravenously; gammacamera images showed bilateral adrenal tumours and uptake corresponding to bone and liver metastases.

${ }^{131}$ I-meta-iodobenzylguanidine is effective in localising phaeochromocytomas, and the technique is safe, specific, and non-invasive.
\end{abstract}

\section{Introduction}

No agent had been found that was capable of imaging the adrenal medulla until the University of Michigan Medical School synthesised iodine-131-labelled meta-iodobenzylguanidine, a guanethidine analogue, which is structurally similar to noradrenaline and taken up by adrenergic storage vesicles. ${ }^{1}$ This correctly localised eight proved phaeochromocytomas. ${ }^{2}$ We describe, for the first time in this country, localisation of disseminated malignant phaeochromocytoma using this substance, made at Southampton.

\section{Case report}

A 52-year-old woman was admitted for investigation of an eightmonth history of widespread bone pain, arthralgia, excessive sweating, Raynaud's phenomenon, palpitations, central chest pain, and weight loss $(8 \mathrm{~kg})$. She was sweating profusely and was wasted, with peripheral

\section{Southampton General Hospital, Southampton SO9 4XY}

HELEN SUTTON, MB, BS, senior registrar in nuclear medicine

PAUL WYETH, MA, PHD, lecturer, department of chemistry, Southampton

University

A P ALLEN, MB, MRCP, senior house officer in rheumatology

O A THURTLE, MB, MRCP, senior registrar in rheumatology

T K HAMES, BSC, PHD, senior physicist

M I D CAWLEY, MD, FRCP, consultant rheumatologis

DUNCAN ACKERY, MB, MSC, consultant in nuclear medicine skin mottling. She had a regular tachycardia ( 150 beats/min). Blood pressure was $150 / 130 \mathrm{~mm} \mathrm{Hg}$. There were bilateral fundal haemorrhages and exudates. Over the next five weeks she had frequent episodes of palpitations and central chest pain associated with Raynaud's phenomenon in the hands and livedo reticularis in the legs. Blood pressure rose to $240 / 160 \mathrm{~mm} \mathrm{Hg}$, returning to $150 / 130$ $\mathrm{mm} \mathrm{Hg}$.

On admission haemoglobin concentration was $9.7 \mathrm{~g} / \mathrm{dl}$ (normochromic). Biochemical profile was normal except for a raised alkaline phosphatase activity of $768 \mathrm{IU} / \mathrm{l}$, fasting calcium concentration $2.56 \mathrm{mmol} / 1(10.3 \mathrm{mg} / 100 \mathrm{ml})$, and calcitonin concentration $0.1 \mu \mathrm{g} / 1$ (normal $<0.08 \mu \mathrm{g} / \mathrm{l}$ ). Twenty-four-hour urine total metanephrines were $340 \mu \mathrm{mol} / 24$ hours $(63 \mathrm{mg} / 24$ hours; normal $<7 \mu \mathrm{mol} / 24$ hours $(<1.3 \mathrm{mg} / 24$ hours)) (metanephrine $39.5 \mu \mathrm{mol} / 24$ hours $(8 \mathrm{mg} /$ 24 hours), normetanephrine $300 \mu \mathrm{mol} / 24$ hours $(55 \mathrm{mg} / 24$ hours)). Radiographs and results of ultrasonography were equivocal, but bone images (technetium-99m-labelled (methylenediphosphonate) showed widespread metastases. Liver images $\left({ }^{9} \mathrm{Tc}^{\mathrm{m}}\right.$-sulphur colloid) showed no focal deposits but suggested a mass above the right kidney. Selective venous sampling was of no help in localising the tumour. Plasma noradrenaline concentration ranged from 5.6 to $12.0 \mu \mathrm{g} / 1$ (normal $<1 \mu \mathrm{g} / \mathrm{l}$ ). Disseminated malignant phaeochromocytoma was diagnosed. Histological confirmation from bone biopsy was not sought because of the risk of pathological fracture. Chemotherapy or radiotherapy was considered not to be indicated. Treatment with phenoxybenzamine $100 \mathrm{mg}$ and propranolol $40 \mathrm{mg}$, both four times daily, and various analgesics resulted in moderately good control of the pain and cardiovascular symptoms, and she was discharged. Two months later she was readmitted with increased bone pain and postural hypotension.

Meta-iodobenzylguanidine was prepared as described by Wieland et al. ${ }^{1}$ Animal toxicity studies in 32 Sprague Dawley rats showed no ill effect from 1200 times the imaging dose intended for man. Metaiodobenzylguanidine was labelled with ${ }^{131} \mathrm{I}$ and administered intravenously. Gamma-camera images showed bilateral adrenal tumours, widespread bone uptake corresponding to the metastases shown on the bone images, and uptake in the liver corresponding to focal metastases present on repeat liver images (figure).

\section{Discussion}

Phaeochromocytoma is rare, occurring in about one in 10000 of the general population. The diagnosis is often made only at necropsy. Of 54 tumours proved at necropsy, 13 had been correctly diagnosed during life. ${ }^{3}$ Plasma or urinary catecholamine concentrations may be diagnostic, but successful management depends on localising the tumour. Imaging 